This item was submitted to Loughborough's Research Repository by the author.

Items in Figshare are protected by copyright, with all rights reserved, unless otherwise indicated.

\title{
Stress analysis of hemispherical shells with single nonradially penetrated
} nozzles

PLEASE CITE THE PUBLISHED VERSION

https://doi.org/10.1016/S0141-0296(96)00016-8

PUBLISHER

(C) Elsevier

VERSION

AM (Accepted Manuscript)

LICENCE

CC BY-NC-ND 4.0

\section{REPOSITORY RECORD}

Ascough, John, W. Malalasekera, and A. Rusu-Casandra. 2019. "Stress Analysis of Hemispherical Shells with Single Nonradially Penetrated Nozzles”. figshare. https://hdl.handle.net/2134/5516. 
This item was submitted to Loughborough's Institutional Repository (https://dspace.lboro.ac.uk/) by the author and is made available under the following Creative Commons Licence conditions.

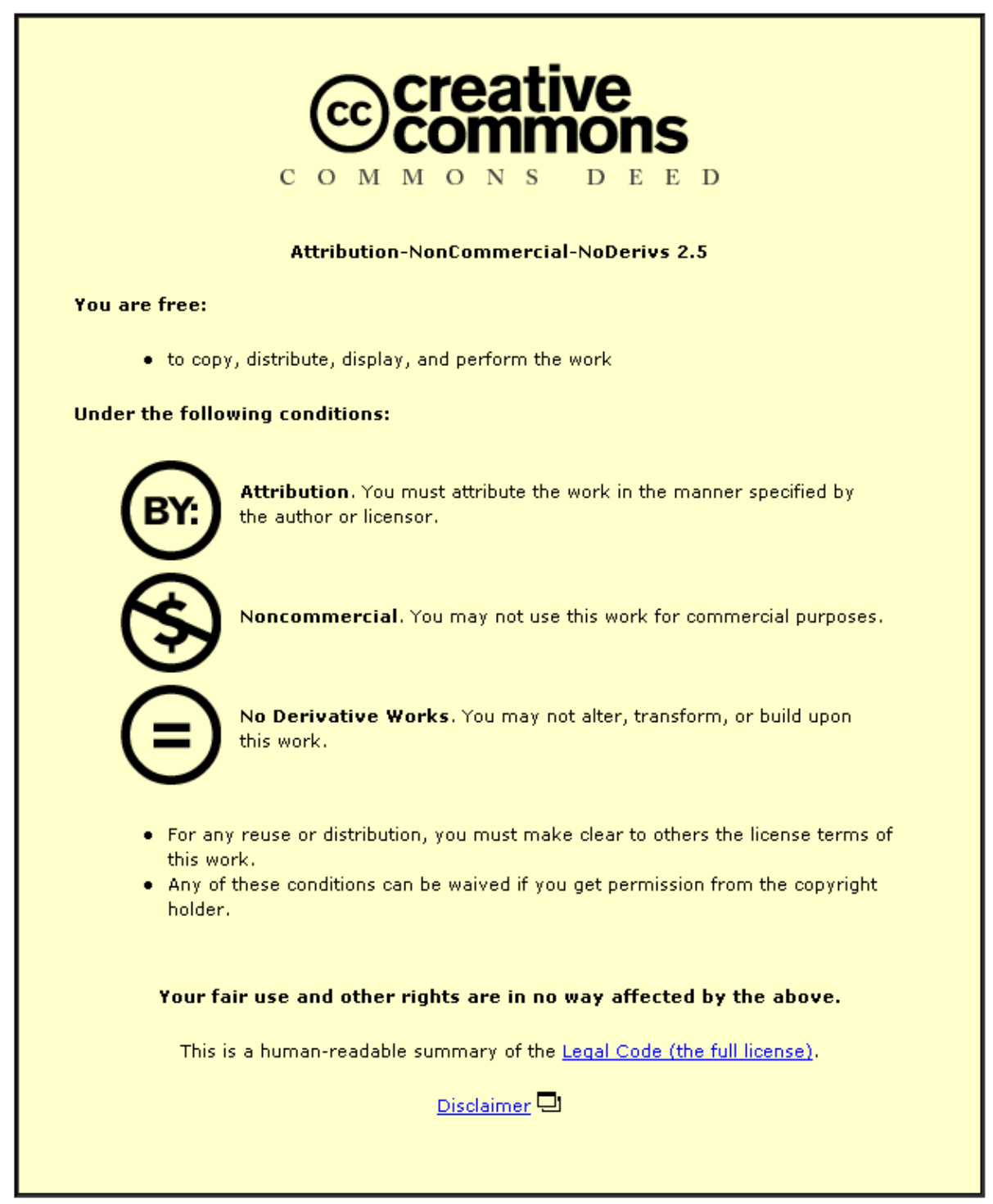

For the full text of this licence, please go to: http://creativecommons.org/licenses/by-nc-nd/2.5/ 


\title{
STRESS ANALYSIS OF HEMISPHERICAL SHELLS WITH SINGLE NONRADIALLY PENETRATED NOZZLES
}

\author{
J. ASCOUGH \\ Department of Mechanical Engineering \\ Loughborough University of Technology \\ Loughborough, Leicestershire LE11 3TU \\ U.K. \\ A. RUSU-CASANDRA \\ Strength of Materials Chair \\ "POLITEHNICA" University of Bucharest \\ 313 Splaiul Independentei Str., 77206 Bucharest \\ ROMANIA \\ W. MALALASEKERA \\ Department of Mechanical Engineering \\ Loughborough University of Technology \\ Loughborough, Leicestershire LE11 3TU \\ U.K.
}

\begin{abstract}
A systematic study is presented of the stress distribution of a cylindrical shell nonradially penetrated into a shallow hemispherical shell under internal pressure, for different angles of inclination of the nozzle. The results from the combined analytical, computational and experimental investigations for a 20-deg nozzle are compared, to demonstrate the accuracy of the theoretical method presented.
\end{abstract}

\section{INTRODUCTION}

The problem of investigating the stresses in compound shells has become an area of increasing interest especially because of safety requirements in nuclear reactor structures and pressure vessels. Since nonradial nozzle-to-spherical shell attachments are commonly used, means for calculating stresses andstrains for such attachments are important in shell structure design.

This paper presents three combined studies which have been conducted to obtain stress distributions for internal pressure in a hemispherical shell having a 20-deg nonradial penetrating nozzle: an analytical study, a finite element analysis, and an experimental investigation. Consideration of different angles of inclination is included. The analytical method is based on closed-form type analyses for cylindrical and shallow spherical shells, using Flugge' (1962) and Vlasov's (1964) equations. Numerical results for the stresses in the compound-shell are obtained using a dedicated computer program developed by the authors. A finite element study is developed, employing the PAFEC (1992) computer program. The calculated results are compared with measured results obtained from an experimental stress analysis of a steel model by means of electrical resistance strain gages. Similar studies have been carried out by Maxwell (1971) and Gwaltney (1973).

\section{NOMENCLATURE}

$R_{c}$ mean radius of cylindrical shell

$R_{s}$ mean radius of spherical shell

$t_{c}$ thickness of cylindrical shell

$t_{s}$ thickness of spherical shell $\phi$ meridional angular coordinate of spherical shell

$\theta$ circumferential angular coordinate of spherical shell

$\mathrm{q}=\mathrm{r} / \mathrm{l}$ 
E Young's modulus

$v$ Poisson's ratio

$\mathrm{p}$ internal pressure

r radius of latitude circle

$\Omega$ angle of obliquity

$\alpha \quad$ axial coordinate of cylindrical shell (= distance along shell / $\mathrm{R}_{\mathrm{C}}$ )

$\beta$ angular coordinate of cylindrical shell

$$
\begin{aligned}
& \ell^{4}=\left(\mathrm{R}_{\mathrm{s}} \mathrm{t}_{\mathrm{s}}\right)^{2} / 12\left(1-\mathrm{v}^{2}\right) \\
& \mathrm{S}=\mathrm{pR}_{\mathrm{s}} / 2 \mathrm{t}_{\mathrm{s}} \text { membrane stress in spherical shell } \\
& \mathrm{K}_{\mathrm{s}}=\mathrm{Et}_{\mathrm{s}}{ }^{3} / 12\left(1-\mathrm{v}^{2}\right) \text { flexural rigidity of } \\
& \quad \text { spherical shell } \\
& \mathrm{k}^{2}=\mathrm{t}_{\mathrm{c}}{ }^{2} / 12 \mathrm{R}_{\mathrm{c}}{ }^{2} \\
& \nabla^{2}()=(), \alpha \alpha+(), \beta \beta \text { for cylindrical shell } \\
& \nabla^{2}()=(), \mathrm{rr}+(1 / \mathrm{r})(), \mathrm{r}+\left(1 / \mathrm{r}^{2}\right)(), \theta \theta \text { for } \\
& \quad \text { spherical shell }
\end{aligned}
$$

\section{ANALYTICAL METHOD}

This method of analysis is more completely described by Yu et. al. (1971), (1973). Besides the assumptions used in classical thin elastic shells applied to both the nozzle and the sphere, for practical reasons the following additional assumptions are made:

- for small angles of inclination of the nozzle, the intersection of the middle surface of the three shells can be approximated as a plane curve

$-\mathrm{R}_{\mathrm{c}} / \mathrm{R}_{\mathrm{s}}<<1$

$-t_{c}$ and $t_{s}$ are constant, although not necessarily equal

- both shells have same $E$ and $v$

- welds keep both shells rigidly connected but do not add to shell thickness

A sketch of the configuration of the compound shell is shown in Fig. 1.

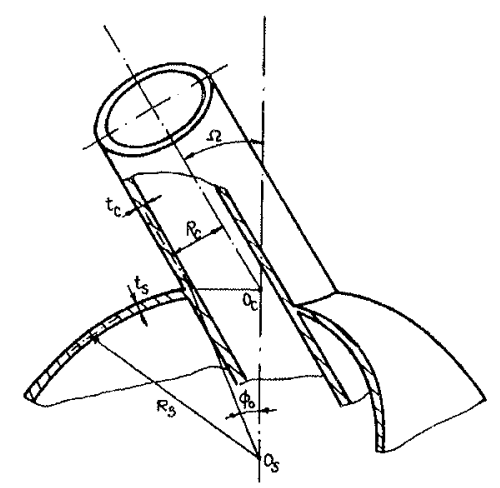

Fig. 1 Configuration of the compound shell.

For the cylindrical shell, the displacements in the axial, circumferential and normal directions can be expressed as follows:

$$
\begin{aligned}
& \mathrm{u}=\mathrm{u}_{0}+\mathrm{u}_{1}+\left[\Phi_{, \alpha \beta \beta}-v \Phi_{, \alpha \alpha \alpha}\right] \\
& \mathrm{v}=-\left[\Phi_{, \beta \beta \beta}+(2+v) \Phi_{, \alpha \alpha \beta}\right] \\
& \mathrm{w}=\mathrm{w}_{1}+\nabla^{4} \Phi
\end{aligned}
$$

where $u_{0}$ is an undetermined rigid body displacement, and $u_{1}=(1 / 2-v) \alpha R_{c}^{2} / E_{c}$ and $\mathrm{w}_{1}=(1-1 / 2 \mathrm{v}) \mathrm{pR}_{\mathrm{c}}^{2} / \mathrm{Et}_{\mathrm{c}}$ are displacements due to the internal pressure. The remaining terms are associated with self-equilibrated edge loadings. $\Phi(\alpha, \beta)$ is the displacement function given by the differential equation of Vlasov (1964): 


$$
\nabla^{4} \nabla^{4} \Phi+\left[\left(1-v^{2}\right) \mathrm{k}^{2}\right] \Phi_{, \alpha \alpha \alpha \alpha}=0
$$

In using Eqs.(1), the rigid body displacements associated with $\Phi(\alpha, \beta)$ were replaced by:

$$
\mathrm{u}^{*}=-\mathrm{d}_{2} \cos \beta ; \mathrm{v}^{*}=-\left(\mathrm{d}_{1}+\mathrm{d}_{2} \alpha\right) \sin \beta ; \mathrm{w}^{*}=\left(\mathrm{d}_{1}+\mathrm{d}_{2} \alpha\right) \cos \beta
$$

where the d's are constants. Therefore, the displacements of the cylindrical shell are obtained by linear combinations of Eqs.(3) and (1) with the appropriate terms associated with $\Phi(\alpha, \beta)$ deleted. The forces, moments and rotations are calculated from Vlasov's (1964) displacement equations. The solutions of the spherical shell chosen for the problem being considered include oscillatory solutions, membrane and inextensional solutions.

For a shallow spherical shell subjected to edge loadings, Reissner's (1946) equations are:

$$
\begin{aligned}
& \nabla^{4} \mathrm{~F}-\left(\mathrm{Et}_{\mathrm{s}} / \mathrm{R}_{\mathrm{s}}\right) \nabla^{2} \mathrm{w}=0 \\
& \nabla^{4} \mathrm{w}+\left(1 / \mathrm{K}_{\mathrm{s}} \mathrm{R}_{\mathrm{s}}\right) \nabla^{2} \mathrm{~F}=0
\end{aligned}
$$

where $F(r, \theta)$ is the stress function and $w(r, \theta)$ is the normal displacement. The following Johnson's (1967) oscillatory functions satisfy Eqs.(4):

$$
\begin{aligned}
& w=\sum_{n=0}^{N}\left[A_{n} \operatorname{ker}_{n}(q)+B_{n} \operatorname{kei}_{n}(q)\right] \cos n \theta \\
& F=\left(\operatorname{Et}_{s} \ell^{2} / R_{s}\right) \sum_{n=0}^{N}\left[A_{n} \operatorname{kei}_{n}(q)-B_{n} \operatorname{ker}_{n}(q)\right] \cos n \theta
\end{aligned}
$$

The total displacements of the shallow spherical shell under internal pressure and self-equilibrated loadings along the coordinate curve, $\phi=$ constant, (which are used to derive expressions for forces, moments and rotations), were taken in the case of method used, as the respective sums of those given by Eqs.(5), inextensional displacements corresponding to nonoscillatory solutions for Eqs.(4) given by Flugge (1962), with terms corresponding to rigid body motions discarded, and the displacements due to internal pressure. The latter are expressed as:

$$
\mathrm{u}_{3}=0 ; \mathrm{v}_{3}=0 ; \mathrm{w}_{3}=(1-v) \mathrm{R}_{\mathrm{s}}^{2} \mathrm{p} / 2 \mathrm{Et}_{\mathrm{s}}
$$

The boundary conditions imposed on each shell are those required for equilibrium and continuity of the composite shell.

According to Yu et.al. (1971), (1973) and Maxwell (1971) no deviation in the nature of the stress distributions in the compound-shells with and without intrusions has been observed. Therefore, for the analytical study only an outwardly protruding nozzle attached to a spherical shell is considered. Three displacements, one rotation, three force components and one moment for each of the two members yield eight junction conditions. Because the junction curve does not coincide with coordinate curves for the shells, the boundary conditions were satisfied by the method of least square boundary point matching.

The computations were performed using a computer program developed by the authors, with the following data: $R_{c}=21.5 \mathrm{~mm}, R_{s}=257 \mathrm{~mm}, t_{c}=4.8 \mathrm{~mm}, t_{s}=6.3 \mathrm{~mm}, \Omega=20^{\circ}, E=2.05^{*} 10^{5} \mathrm{MPa}$, $v=0.3, M=19$ (number of matching points), $N=10$ (number of terms retained in the series). The stress components at $\theta=0^{\circ}, 45^{\circ}, 90^{\circ}, 135^{\circ}, 180^{\circ}$ were normalised by dividing by the membrane stress in the spherical shell. The dimensionless stresses at $\theta=0^{\circ}, 90^{\circ}$ are plotted in Figs. 2 and 3. 

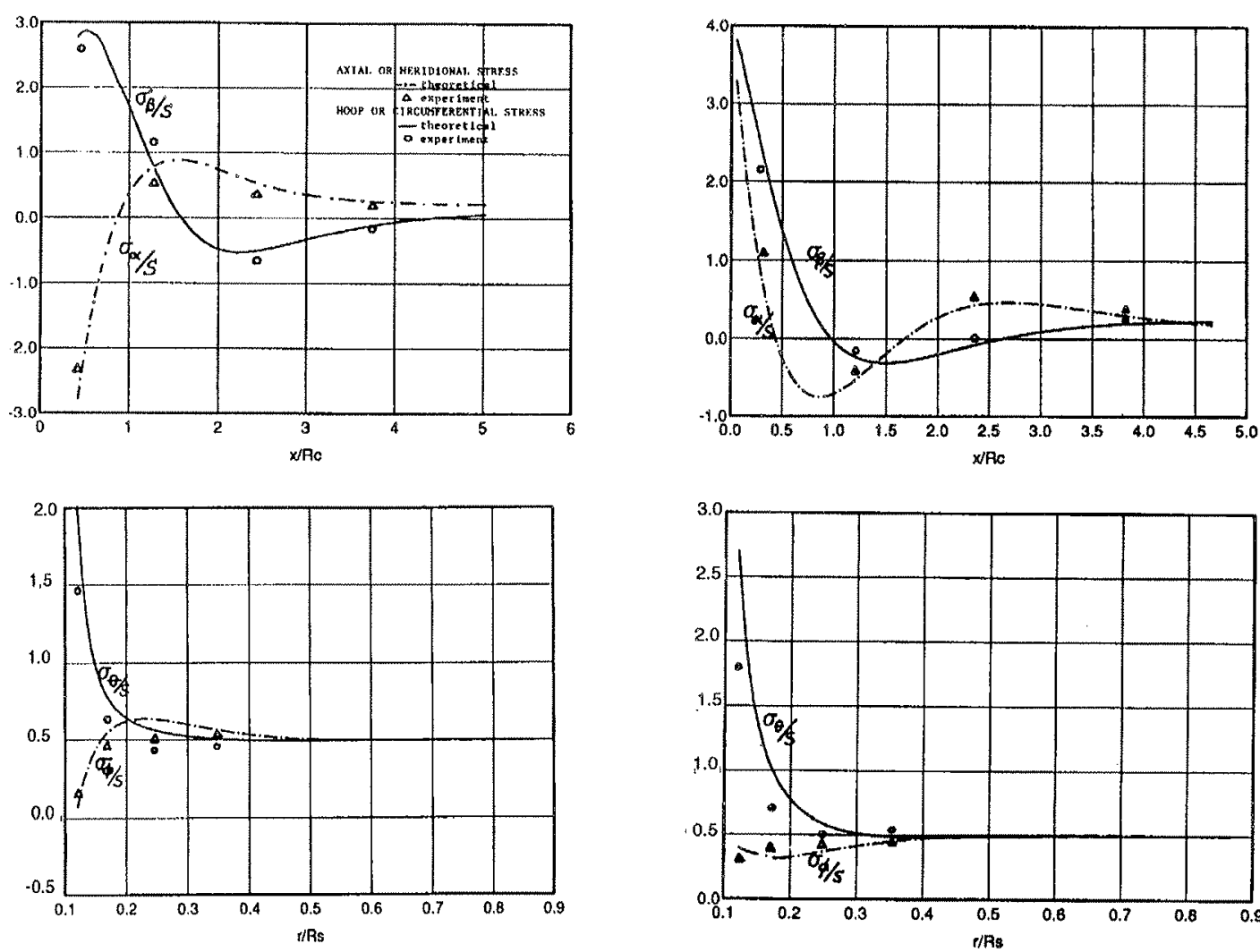

a) inner surface

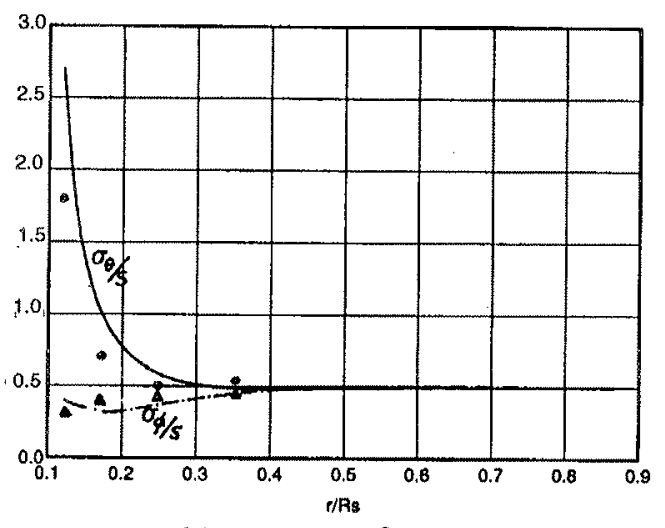

b) outer surface

Fig.2 Stress distribution 0-deg plane
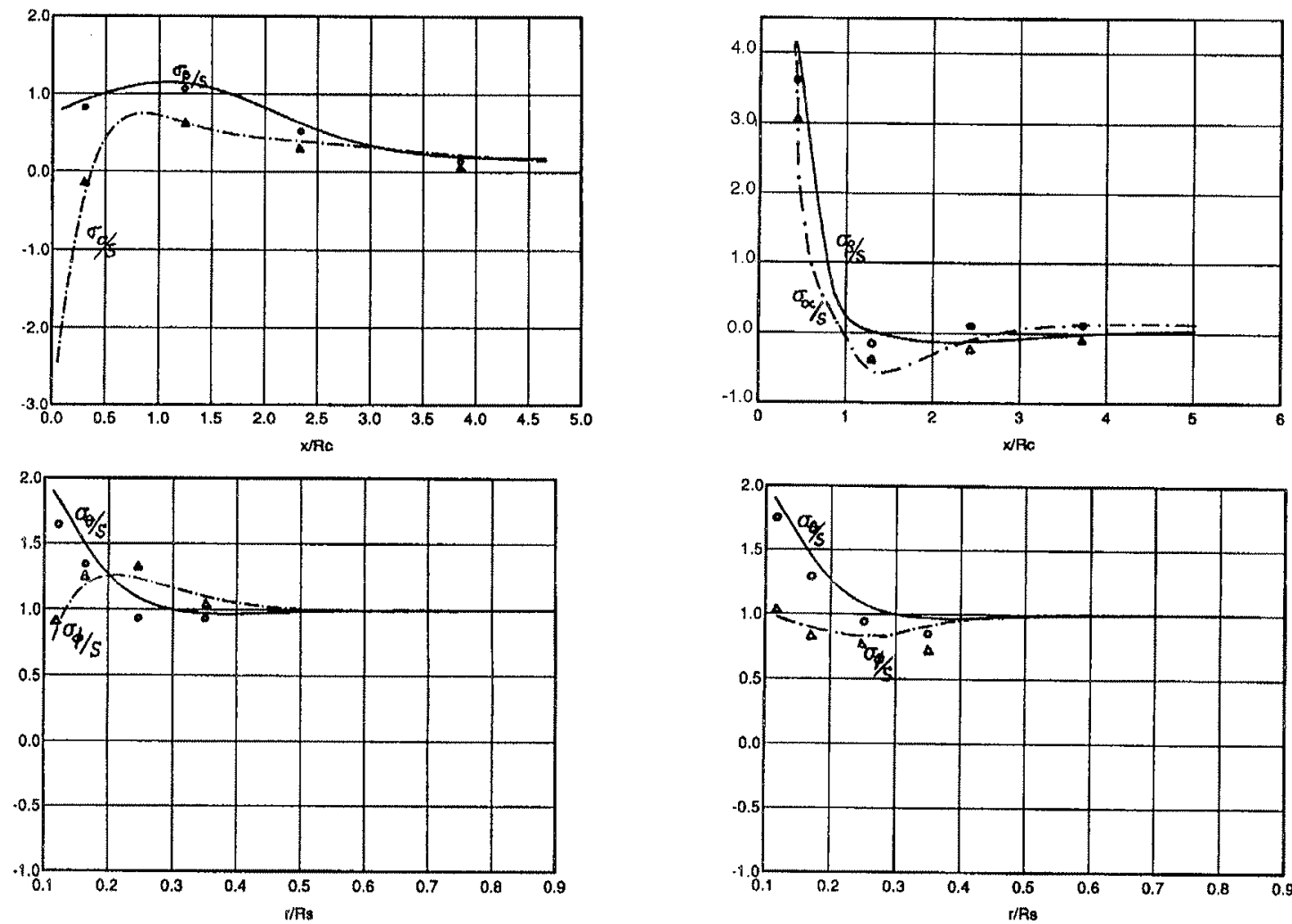

a) inner surface

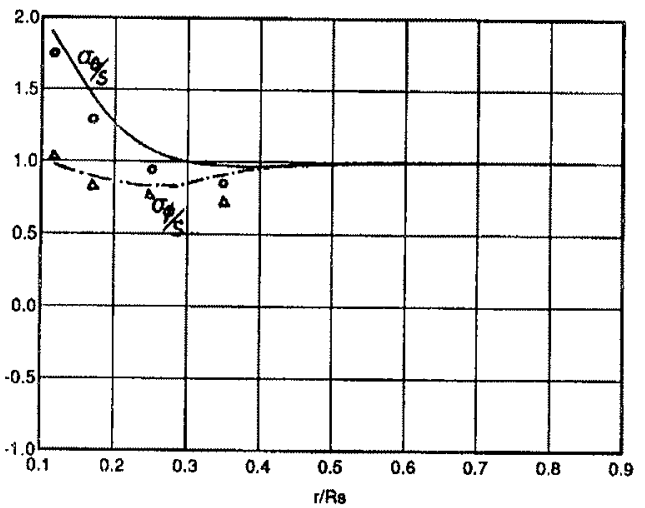

b) outer surface

Fig.3 Stress distribution $90-$ deg plane 


\section{FINITE ELEMENT ANALYSIS}

For the same spherical shell having a nonradial penetrating nozzle, the analysis was carried out using the PAFEC (1992) finite element computer program. Since the primary objective of this study was to determine the stress distributions at the junction, only one-half of the nozzle and onequarter of the spherical vessel were modeled. In view of the symmetry of the geometry and applied load about the X-Y plane (Fig.4), a finite element mesh consisting of 768 elements and 2433 nodes was generated for the model, using the curved shell element of Ahmad et.al.(1990).This is defined by eight nodal points having six degrees of freedom at each node. Consistent boundary conditions were chosen to reflect half symmetry of the finite element mesh and the applied internal pressure, with an arbitrary chosen value of $1 \mathrm{MPa}$.

The plot of the finite element mesh and its distorsion is presented in Fig.4. Distributions of hoop or circumferential stresses $\left(S_{\mathrm{Xx}}\right)$ and axial or meridional stresses $\left(S_{\mathrm{yy}}\right)$, depending wheter the region considered is the cylinder or the sphere have been plotted for $0,45,90,135,180$-deg planes.

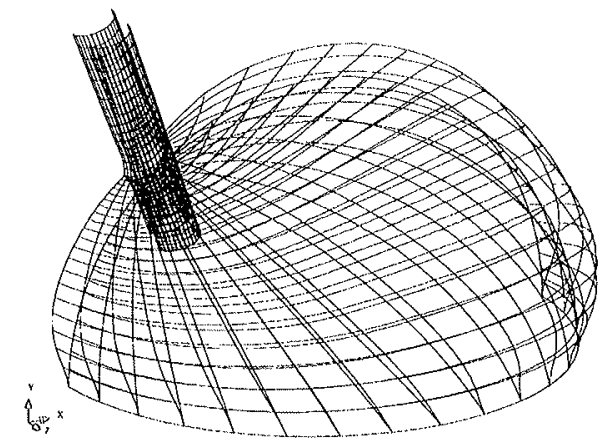

Fig.4 Distorsion of the finite element mesh

Figs. 5 and 6 present the stresses for 0 and 90 -deg planes.
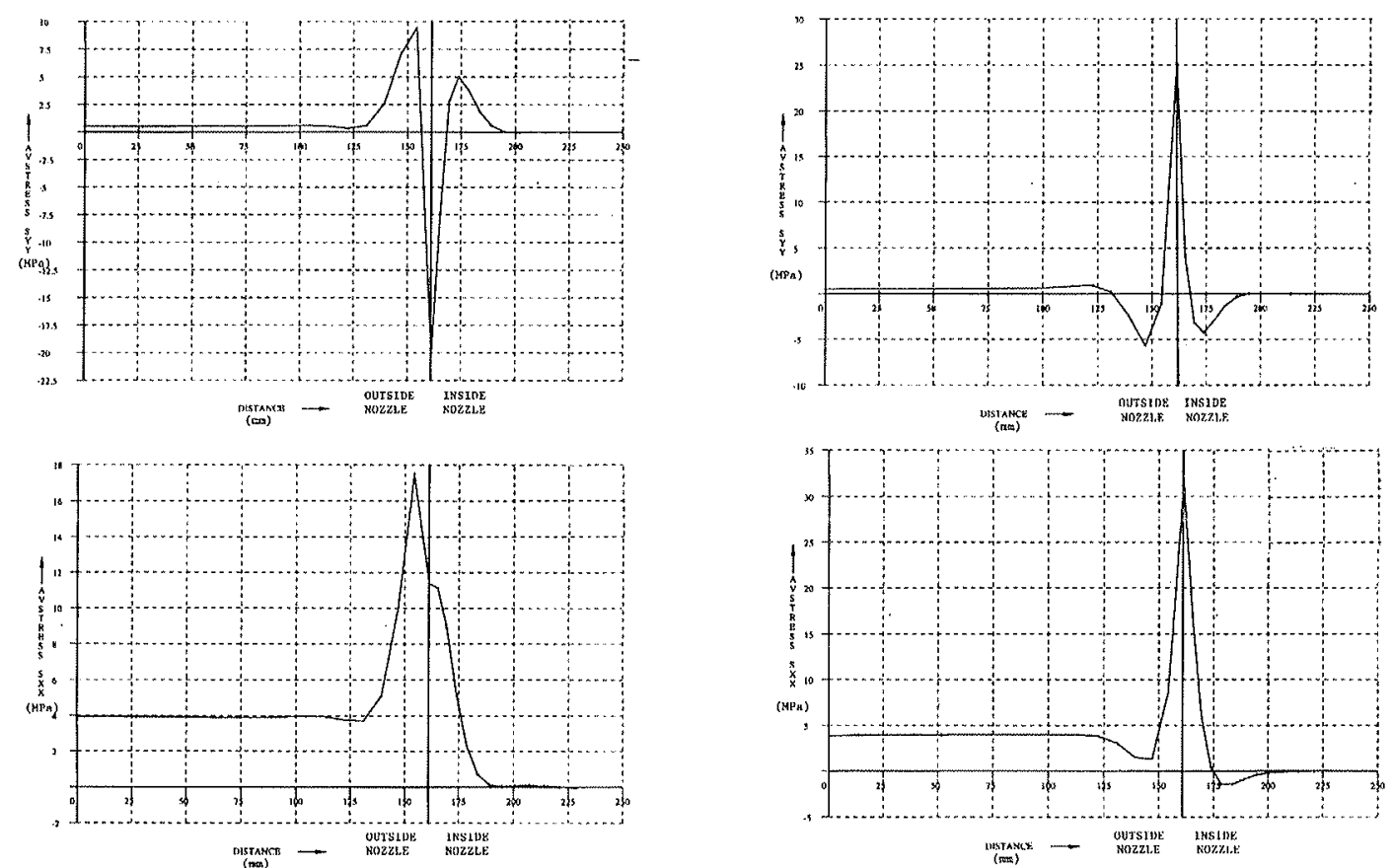

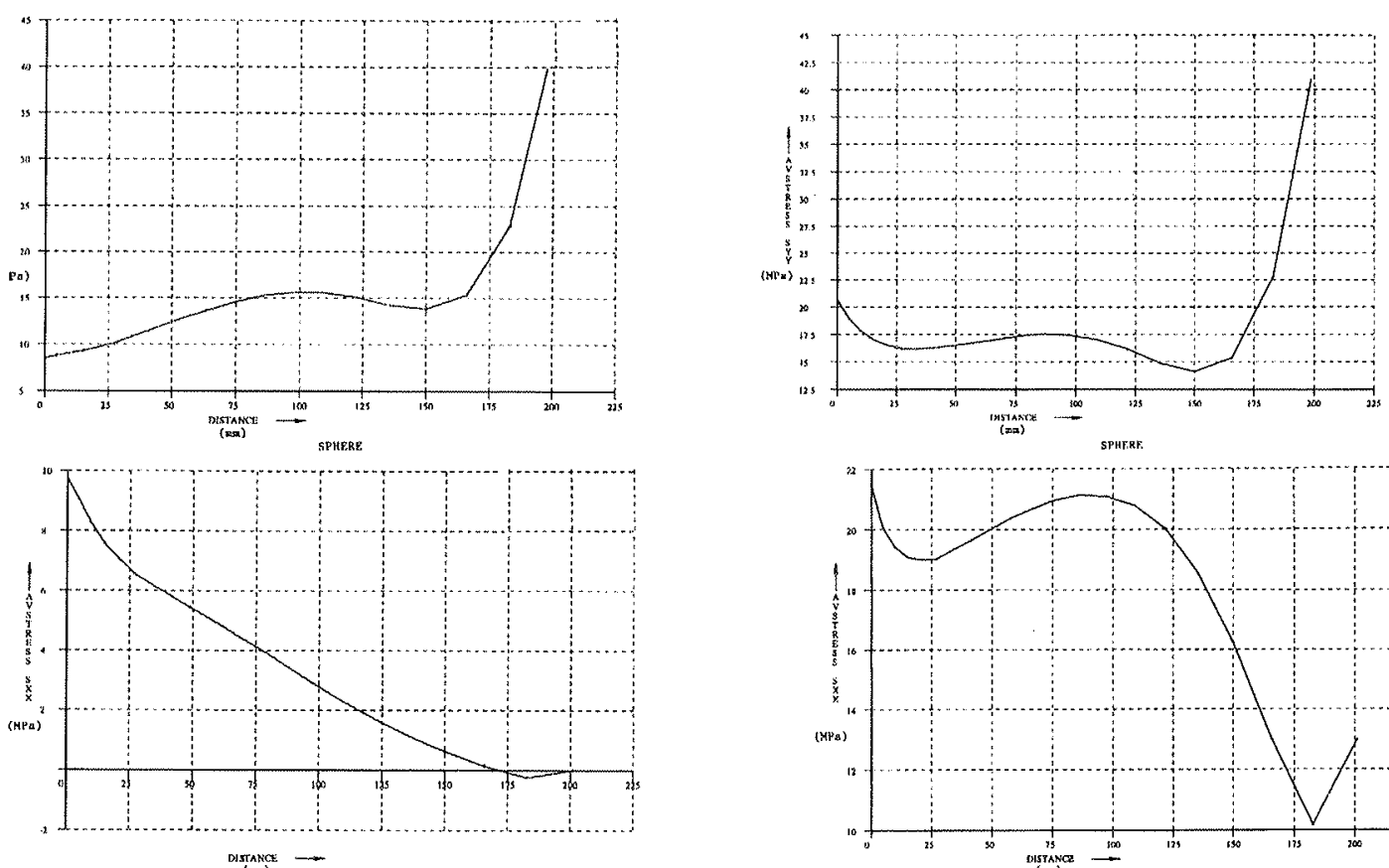

a) inner surface

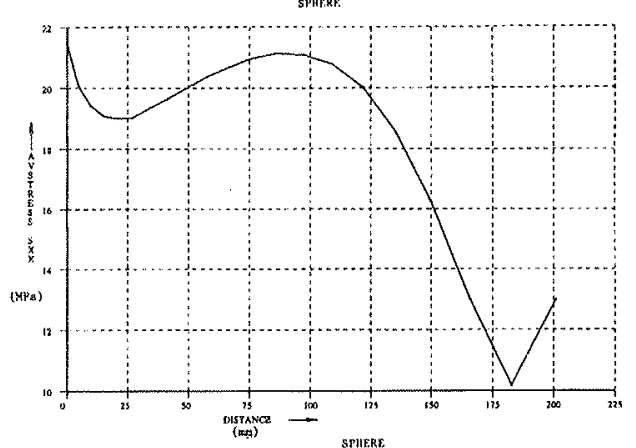

b) outer surface

Fig.5 Stress distribution 0-deg plane
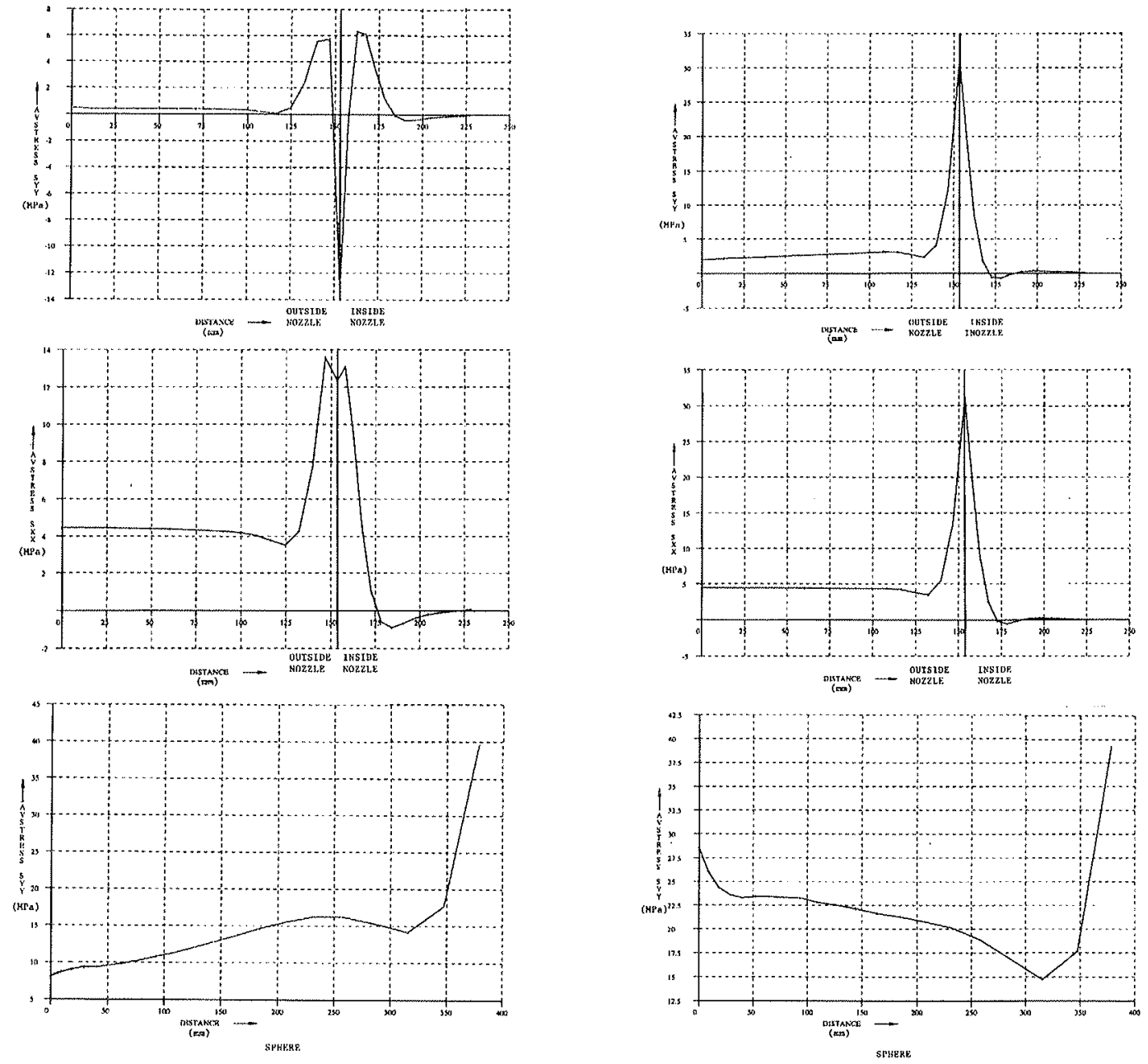


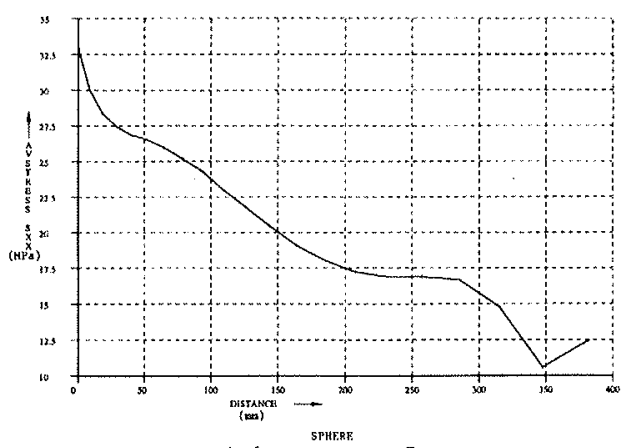

a) inner surface

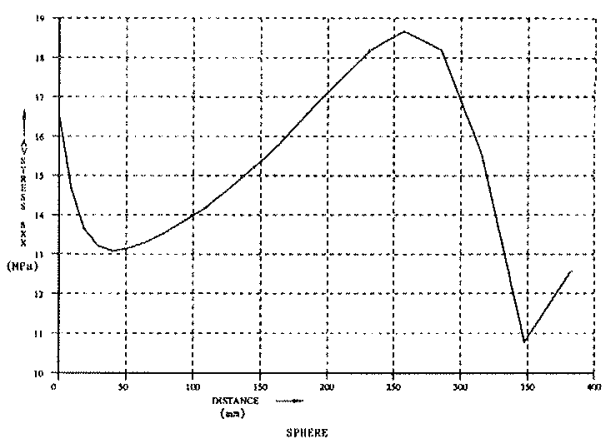

b) outer surface

Fig.6 Stress distribution 90-deg plane

The calculated stress components were normalized and compared with the analytical results. The maximum error was less than $15 \%$, with the calculated stresses being smaller. Although the discrepancy is acceptable for practical design purposes, it would be necessary to take particular care in modeling the junction. It should be noted that the stresses near the base of the hemisphere are higher because of the fixed boundary conditions.

The contour plots of the von Mises stresses are shown in Fig.7. The major conclusion is that the critical stress occurs in the acute inside corner of the intersection.

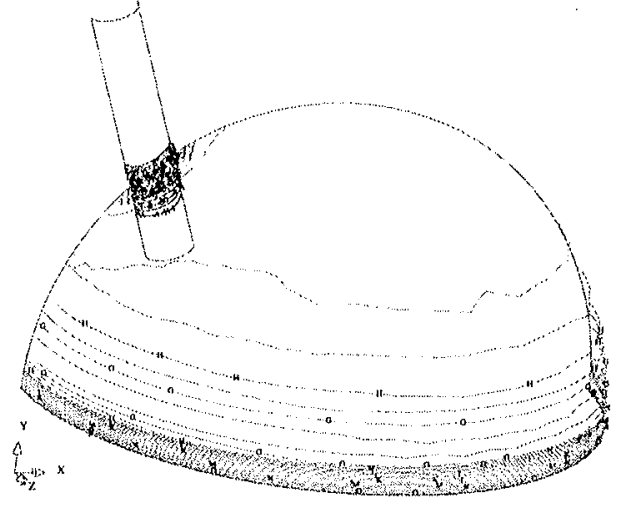

a) inner surface

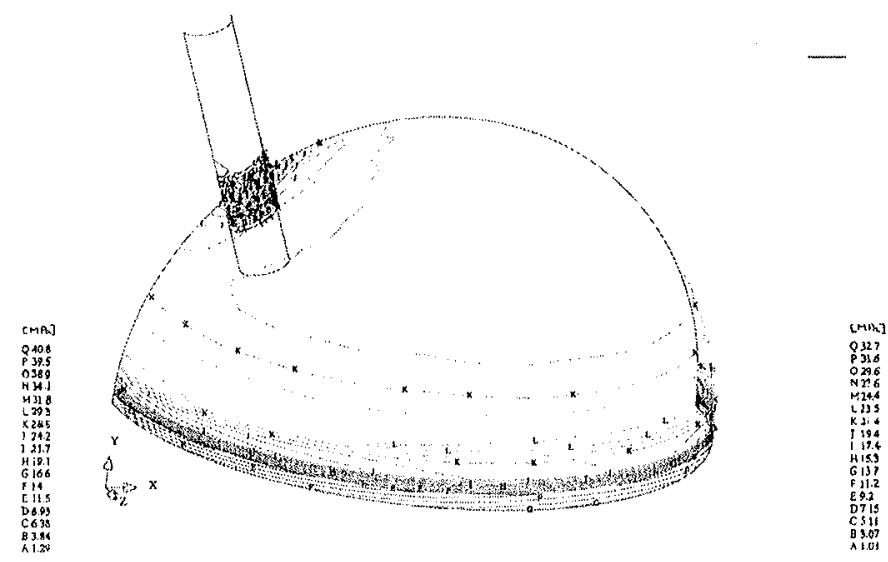

b) outer surface

Fig.7 Stress contour plots (von Mises)

\section{EXPERIMENTAL INVESTIGATION}

An experimental investigation was conducted to provide data for use in analytical and finite element method development and assessment.Therefore a machined steel model was extensively straingaged in the high stress regions. The dimensions of the model coincided with those for the models used in the numerical application of the analytical method and finite element analysis (Fig.8). The nozzle was welded to the hemispere with a full penetration weld. It should be noted that there is essentially no fillet at the junction; thus, an idealized configuration was obtained so that maximum benefit could be derived from the results. The model was instrumented with foil resistance strain-gage rosettes bonded to both inner and outer surfaces of the shells. The gages were arranged on five axial planes around the nozzle and extended in great circles on the shell (Fig.9). 


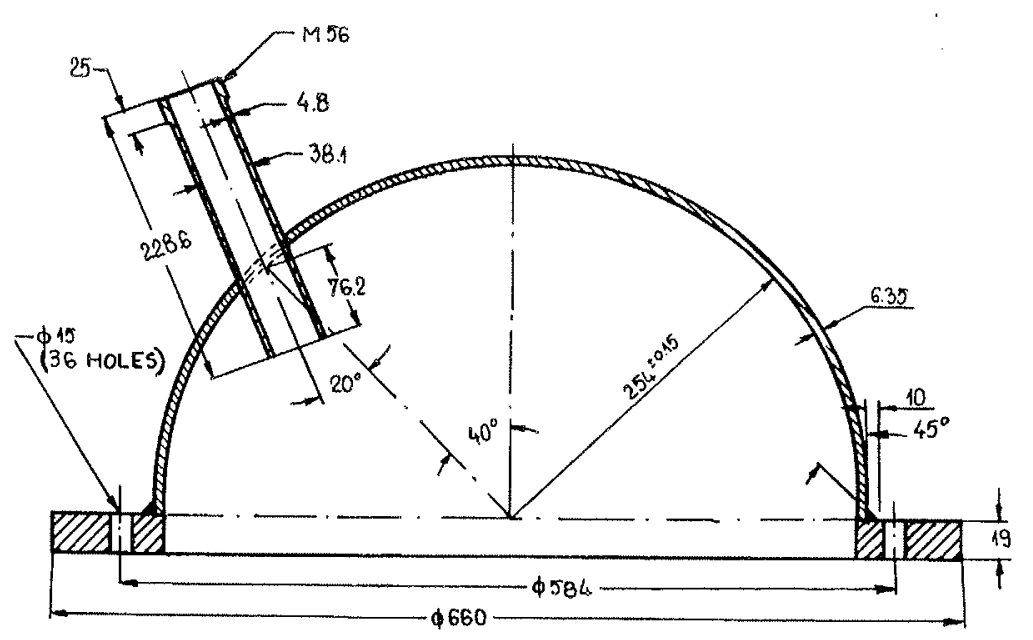

Fig.8 Cross-sectional view of hemisphere and nozzle assembly

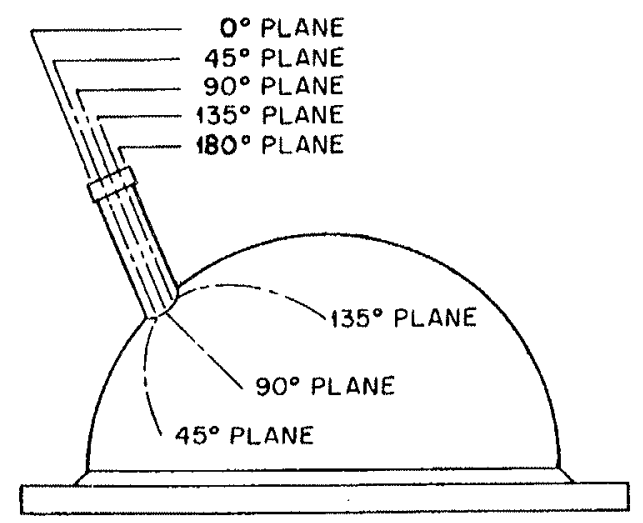

Fig.9 Gages lines for nonradial nozzle-to-shell attachment

On all surfaces, except the inside surface of the nozzles, the nearest rosettes were located $1 \mathrm{~mm}$ from the intersection. After gaging, the hemisphere was bolted to a thick steel plate, using a rubber gasket for a seal. The pressure load was applied hydraulically. Strain gage readings were at zero load, one-third load, two-thirds load, full load and then again at zero load, so that linearity and drift of strain gages could be checked.

The strain data obtained from the test were reduced by means of a computer program, to give normalized stresses in tabulated form at each rosette position. An examination of stress distributions along 0 and 90-deg planes (Figs.2 and 3) reveals that the theoretical and experimental data are qualitatively compatible in the general trends. The slight deviations are believed to be a result of the $76.2 \mathrm{~mm}$ intrusion.

\section{CONCLUSIONS}

The results obtained for stress distributions in the attachment region of a hemispherical shell with a single nonradial penetrating nozzle using analytical, computational and experimental methods, although similar, are not the same. Differences between theoretical and measured values were noticeable for the stresses in the immediate vicinity of the intersection curve. 
Therefore, the comparison of these results led to the following conclusions:

- the analytical model can be improved by finding more appropriate equations which approximate the junction curve

- the finite element model can also be improved by using 3-D isoparametric elements in the attachment region (for distances having the same order as the thickness of the shells), due to the fact that the stress state is tridimensional and has a complex configuration. However it will be useful to carry out mesh convergence studies

- the analyses have been restricted to linear elastic theory. Due to the large stress gradients along the junction curve, the linear theory may fail, so non-linear effects might play an important role

-for different angles of obliquity of the nozzle ( $\Omega=10^{\circ}, 15^{\circ}, 30^{\circ}$ ), the calculated results obtained have not been compared with the experimental values; therefore, further study is required to find out the maximum angle that can be utilized to obtain accurate results.

However, the method should find important use in shell-structure design within the established range of applicability, over which usefull solutions can be found,

\section{REFERENCES}

1. Ahmad, S., Iron, B.M., Zienkiewicz, O.C. (1970). "Analysis of Thick and Thin Shell Structures by Curved Finite Elements." International Journal for Numerical Methods in Engineering, USA, 2, 419-451.

2. Flugge, W. (1962). "Stresses in Shells." Springer-Verlag, Germany.

3. Gwaltney, R.C., Greenstreet, W.L. (1973). "Comparison of Theoretical and Experimental Stresses for Spherical Shells Having Single Nonradial Nozzles." Second International Conference on Pressure Vessel Technology, San-Antonio, USA, 85-103.

4. Johnson, D.E. (1967). "Stresses in a Spherical Shell With a Nonradial Nozzle." Journal of Applied Mechanics, USA, 34, 299-307.

5. Maxwell, R.L. (1971). "Experimental Stress Analysis of the Attachment Region of Hemispherical Shells With Single Attached Nozzles." Pressure Vessels \& Piping Conference, San Francisco, USA.

6. Reissner, E. (1946). "Stresses and Small Displacements of Shallow Spherical Shells, I and II." Journal of Mathematics and Physics, USA, 25, 80-85, 279-300.

7. Vlasov, V.Z. (1964). "General Theory of Shells and Its Application in Engineering." NASA, USA.

8. Yu, J.C.M., Chen, C.H., Shaw, W.A. (1971). "Stress Distribution of a Cylindrical Shell Nonradially Attached to a Spherical Pressure Vessel." Pressure Vessels \& Piping Conference, San Francisco, USA.

9. Yu, J.C.M., Shaw, W.A., Chen, C.H. (1973). "Stress Distribution of a Cylindrical Shell Nonradially Penetrated into a Spherical Pressure Vessel." Second International Conference on Pressure Vessel Technology, San-Antonio, USA, 115-128.

10. PAFEC (1992). "Data Preparation User Manual." Pafec Ldt., Nottingham, UK. 